Check for updates

Cite this: Mater. Adv., 2020, 1, 1113

Received 26th April 2020, Accepted 16th June 2020

DOI: 10.1039/d0ma00247j

rsc.li/materials-advances

\section{Investigation of the photoluminescence and novel thermoluminescence dosimetric properties of $\mathrm{NaGdF}_{4}: \mathrm{Tb}^{3+}$ phosphors $\dagger$}

\author{
Preeti Padhye Kulkarni, ${ }^{a}$ Kishor H. Gavhane, ${ }^{a}$ Mahesh S. Bhadane, ${ }^{b}$ \\ Vasant N. Bhoraskar, ${ }^{a}$ Shailendra S. Dahiwale ${ }^{a}$ and Sanjay D. Dhole iD *a
}

\begin{abstract}
The hexagonal phase $\beta-\mathrm{NaGdF}_{4}: x \% \mathrm{~Tb}^{3+}(x=0$ to $5 \%$ ) phosphor crystals with uniform morphology and considerable monodispersity were synthesized via a tri-sodium citrate-assisted hydrothermal route. The photoluminescence studies showed the strong emission lines corresponding to ${ }^{5} D_{4} \rightarrow{ }^{7} F_{J}(J=6,5,4,3)$ transitions with a prominent ${ }^{5} \mathrm{D}_{4} \rightarrow{ }^{7} \mathrm{~F}_{5}$ green emission transition at $540 \mathrm{~nm}$. The as-prepared samples were annealed at different temperatures $\left(200-800{ }^{\circ} \mathrm{C}\right.$ ), and the effect of thermal treatment on their structural, morphological, surface, photoluminescence and thermoluminescence properties were studied. A comparative study of pristine and annealed samples revealed phase alteration to the mixed (i.e. cubic and hexagonal) phase along with morphology transformation at higher annealing temperatures. The photoluminescence emission intensity was remarkably enhanced ( $\sim 9$ times) at $700{ }^{\circ} \mathrm{C}$ owing to the reduction in non-radiative processes from the surface and the volatilization of luminescence quenching $(-\mathrm{OH})$ groups, which were corroborated by surface FTIR studies. The systematic study of the optimum concentrations of impurities and thermal treatment were studied to achieve high thermoluminescence ( $T L$ ) efficiency. The best TL dosimetric glow curve was obtained for $\mathrm{NaGdF}_{4}: 3 \% \mathrm{~Tb}^{3+}$ annealed at $700{ }^{\circ} \mathrm{C}$, which peaked at $230{ }^{\circ} \mathrm{C}$, signifying deeper traps. The $\mathrm{NaGdF}_{4}: 3 \% \mathrm{~Tb}^{3+}$ phosphor showed a linear response over a very wide range of gamma doses from 100 Gy to $20 \mathrm{kGy}$, revealing that the $\mathrm{NaGdF}_{4}: \mathrm{Tb}^{3+}$ phosphor was quite well suited for high gamma dose measurements and their respective applications. Fading and reproducibility studies showed low fading and excellent reproducibility characteristics. The $T_{m}-T_{\text {stop }}$ technique in combination with the Initial Rise Method (IRM) was used to identify the number of overlapped TL glow peaks and trap level analysis. The kinetic parameters, such as activation energy $(E)$, frequency factor (s), and order of kinetics (b), were estimated by the Glow Curve Deconvolution (GCD) method. The Figure of Merit (FOM) value was found to be $2.2 \%$. The trapping parameters resulting from the experimental $T_{m}-T_{\text {stop }}$ study and theoretical GCD match closely and are in good agreement with each other. Thus, along with high luminescence efficiency, the newly explored strong thermoluminescence properties of $\mathrm{NaGdF}_{4}: \mathrm{Tb}^{3+}$ make them potential phosphor materials and could provide new avenues into other applications in radiation dosimetry such as agriculture/food sciences, archeological sciences, space dosimetry, etc.
\end{abstract}

\section{Introduction}

Thermoluminescence (TL) is the emission of light from a crystalline material that is either inorganic, a semiconductor, or an insulator when it is heated after its exposure to some ionizing radiation. ${ }^{1}$ Accordingly, when any ionizing radiation is incident upon a crystal, some energy is dissipated by various processes such as heat and

\footnotetext{
${ }^{a}$ Microtron Accelerator Laboratory, Department of Physics, Savitribai Phule Pune University, Pune, 411007, MH, India. E-mail: sanjay@physics.unipune.ac.in

${ }^{b}$ Department of Physics, Rayat Shikshan Sanstha's Dada Patil Mahavidyalaya, Karjat, 414402, MH, India

$\dagger$ Electronic supplementary information (ESI) available. See DOI: 10.1039/ d0ma00247j
}

light and some amount of energy is absorbed and stored in the lattice at the luminescent centers or defect sites, etc. Upon subsequent heating of the crystal, this stored energy is released and a fraction of it can be emitted as visible light in form of a TL glow curve/peak. ${ }^{2}$ The positions, shapes and intensities of the glow peaks are related to the various TL parameters, which provide very valuable information about the trapped states/charges and energy transfer processes in a crystalline lattice resulting in the emission of light. $^{3}$ It is a very powerful technique that is used for dose measurement, i.e., estimations of doses of ionizing radiation, as the energy absorbed by the phosphor during irradiation and the TL intensity on stimulation (heating) is proportional to the radiation doses. ${ }^{4}$ The dosimetric properties of TL materials mainly depend on the kinetic parameters of its glow peak. Kinetic parameters provide 
valuable information about the thermoluminescence mechanism in a material. The most significant TL parameters, namely, trap depth $(E)$ or the activation energy, which is the thermal energy required to liberate the trapped electrons and holes, the order of kinetics $(b)$ and the frequency factor $(s)$, can be evaluated by TL glow peak analysis. Existing methods for peak analysis and activation energy $(E)$ and frequency factor $(s)$ determination are principally comprised of Peak Shape (PS), Initial Rise (IR), Isothermal Decay (ID), and Variable Heating Rate (VHR) methods. ${ }^{5,6}$

Thermoluminescence dosimetry (TLDs) materials have found many useful applications in various fields of radiation dosimetry in personnel and environmental monitoring, medical/clinical dosimetry, agriculture/food irradiation sciences, i.e. dose measurement in food preservation, radiation sterilization of seed, etc., archeological sciences, high-dose dosimetry, retrospective dosimetry and space dosimetry. $^{2,7}$

A number of thermoluminescent dosimeters (TLD)-based systems are now commercially available. $\mathrm{CaSO}_{4}$ :Dy (TLD-900), LiF-based phosphors such as LiF:Mg,Cu,P (LiF-TLD 700H), LiF:Mg,Ti (TLD-100), $\mathrm{Li}_{2} \mathrm{~B}_{4} \mathrm{O}_{7}: \mathrm{Mn}$ (TLD-800), $\mathrm{CaF}_{2}$ :Dy (TLD-200), $\mathrm{Al}_{2} \mathrm{O}_{3}: \mathrm{C}$, are efficient and commercially available phosphors. ${ }^{2,8-10}$ However, owing to the increasing use of the TL technique, efforts are still being made to improve the TL characteristics and sensitivity of phosphor materials either by thermal treatment or by impurity doping. Attempts are also being made to develop new phosphor materials with improved TL characteristics.

It is worth mentioning that lanthanide ion-doped luminescent nanomaterials, specifically sodium rare-earth fluoride $\left(\mathrm{NaREF}_{4}: \mathrm{Ln}^{3+}\right)$ phosphors, are receiving a great deal of interest in the field of science and technology due to their highly efficient and extraordinary photoluminescence properties. The lanthanide ion-doped phosphors have been extensively studied owing to their fascinating wide range of applications in multicolor displays, opto-electronics, lasers, solar cells, photocatalysis, biomedical sciences, theranostics probes, sensing, anti-counterfeiting, security printing, etc. ${ }^{11-16}$ The outstanding intricate spectroscopic properties of $\mathrm{Ln}^{3+}$-doped phosphors originates from parity forbidden intra $\mathrm{f}-\mathrm{f}$ transitions that are shielded by filled $5 s^{2}$ and $5 p^{6}$ orbitals. ${ }^{17}$ This unique electronic configuration renders fascinating properties to these materials, such as emissive transitions in a broad spectral region, less sensitivity to the surrounding environment, large Stokes and anti-Stokes shifts ( $>200 \mathrm{~nm}$ ), sharp and narrow emission bands (FWHM $\sim 10 \mathrm{~nm}$ ), long-lived luminescence (milliseconds), low intermittency and background fluorescence, and high photostability. ${ }^{18-20}$

Since lanthanide dopants suffer from low molar absorption coefficients $\left(\varepsilon=1-10 \mathrm{M}^{-1} \mathrm{~cm}^{-1}\right),{ }^{21}$ for efficient electronic transitions between rare-earth energy levels and to effectively utilize the novel luminescence of lanthanide dopant ions, it is necessary to choose appropriate host lattice materials. Fluoride host materials provide some distinct advantages as compared to oxide materials or other rare-earth compounds such as sulphates, phosphates, and vanadates, owing to their unique properties like high coordination number, high ionicity of rare earth-to-fluorine $\left(\mathrm{RE}^{3+}-\mathrm{F}^{-}\right)$bonds, intrinsic low phonon energy, wide band gap, chemical stability, electron acceptor behavior, and anionic conductivity. ${ }^{22,23}$ Among the various investigated fluoride host materials, sodium rare-earth fluorides $\left(\mathrm{NaREF}_{4}\right)$, particularly $\mathrm{NaGdF}_{4}$, are of special interest. The $\mathrm{NaGdF}_{4}$ is considered as one of the most versatile and outstanding host materials because of its excellent luminescence efficiency due to half-filled $4 \mathrm{f}$ orbitals resulting in minimal non-radiative electronic transitions, wide band gap, high refractive index, low phonon energy, and chemical, thermal, and environmental stability. ${ }^{24}$ Also, the $\mathrm{Gd}^{3+}$ ion serves as an ideal sensitizer or intermediate to activate the specific luminescence of $\mathrm{Ln}^{3+}$ ions via the non-radiative energy transfer mechanism, inducing intense emissions in the visible region. Moreover, the presence of $\mathrm{Gd}^{3+}$ renders paramagnetic properties; thus, the $\mathrm{Ln}^{3+}$ doped $\beta-\mathrm{NaGdF}_{4}$ phosphors can be used as multifunctional magneto-luminescent probes. $^{25,26}$

In this contribution, we report the structural, morphological, photoluminescence and thermoluminescence properties of $\mathrm{NaGdF}_{4}: \mathrm{Tb}$ phosphors synthesized via the tri-sodium citrateassisted hydrothermal route. $\mathrm{NaGdF}_{4}: x \% \mathrm{~Tb}(x=0$ to $5 \%)$ were prepared and their structural, morphological and photoluminescence properties were studied. It is well demonstrated that thermoluminescence properties in the phosphor material are greatly modified by the type of impurity/dopant, its concentration and the thermal treatment. Enlightened by this point, to explore and optimize the $\mathrm{NaGdF}_{4}: x \% \mathrm{~Tb}$ phosphor for efficient thermoluminescence properties, we attempted to anneal the as-prepared $\mathrm{NaGdF}_{4}: x \% \mathrm{~Tb}$ phosphor samples at different temperatures from $200-800{ }^{\circ} \mathrm{C}$. The photoluminescence properties are also greatly influenced by the thermal treatment, ${ }^{27}$ thus, the influence of thermal treatment on the structural, morphological, surface and photoluminescence properties of $\mathrm{NaGdF}_{4}: \mathrm{Tb}$ phosphors were also studied. Thermoluminescence glow curves, dose responses, fading characteristics, and reproducibility were studied. The number of glow peak components and trapping parameters/kinetic parameters such as the activation energy and kinetics order were investigated experimentally by $T_{\mathrm{m}}-T_{\text {stop }}$ analysis in combination with the initial rise method (IRM), the activation energy- $T_{\text {stop }}$ method and theoretically by the glow curve deconvolution (GCD) method. Potential photoluminescence, magnetic properties and consequent applications of $\mathrm{NaGdF}_{4}$ phosphors have been explored to some extent. Thermoluminescent dosimetric applications are an important field of science and technology. However, unfortunately, no serious attention has been paid to exploring the thermoluminescence dosimetric properties of $\mathrm{Tb}^{3+}$-doped $\mathrm{NaGdF}_{4}$ phosphors in the literature to date. To the best of our knowledge, for the first time, we report the thermoluminescence dosimetric properties of the gamma-irradiated $\mathrm{NaGdF}_{4}$ phosphor activated by $\mathrm{Tb}^{3+}$ ions.

\section{Materials and methods}

\subsection{Materials}

All the chemicals were of analytical grade and were used as-received without any further purification. The rare earth oxides, gadolinium oxide $\left(\mathrm{Gd}_{2} \mathrm{O}_{3}\right)$ (purity $\geq 99.89 \%$ ), and terbium oxide $\left(\mathrm{Tb}_{2} \mathrm{O}_{3}\right)$ (purity $\geq 99.89 \%$ ) were purchased from Sigma Aldrich Inc. Sodium fluoride $(\mathrm{NaF})$ and tri-sodium citrate dihydrate $\left(\left(\mathrm{Na}_{3} \mathrm{C}_{6} \mathrm{H}_{5}\right)_{7} \cdot 2 \mathrm{H}_{2} \mathrm{O}\right)$ were received from Thomas Baker Chemicals Pvt. Ltd. Deionized water was used throughout the experiments. Rare earth nitrate stock 
solutions were prepared by dissolving the corresponding rare earth oxides $\left(\mathrm{Gd}_{2} \mathrm{O}_{3}\right.$ and $\left.\mathrm{Tb}_{2} \mathrm{O}_{3}\right)$ in nitric acid at elevated temperatures $\left(\sim 80{ }^{\circ} \mathrm{C}\right)$.

\subsection{Synthesis}

All of the doping ratios of $\mathrm{Ln}^{3+}$ are molar in our experiments. In a typical procedure for the preparation of $\beta-\mathrm{NaGdF}_{4}: x \% \mathrm{~Tb}^{3+}$ $(x=0,0.5,1,2,3,4,5 \%)$ crystals, aqueous solutions of $\mathrm{Gd}\left(\mathrm{NO}_{3}\right)_{3}$ and $\mathrm{Tb}\left(\mathrm{NO}_{3}\right)_{3}(0.2 \mathrm{M})$ were added into $30 \mathrm{~mL}$ of aqueous solution containing $2 \mathrm{mmol}$ of tri-sodium citrate $(0.5882 \mathrm{~g})$ to form the metal-citrate complex. After vigorous stirring, $2 \mathrm{M}$ of $\mathrm{NaF}$ solution was added drop-wise into the above solution under stirring. After agitation for several minutes, the solution was transferred into a stainless steel autoclave with Teflon liner of $80 \mathrm{~mL}$ capacity, sealed and heated at $180{ }^{\circ} \mathrm{C}$ for $24 \mathrm{~h}$. After that, the autoclave was cooled to room temperature and the resulting product was separated centrifugally and washed several times with distilled water and absolute ethanol. The product was dried under vacuum at $80{ }^{\circ} \mathrm{C}$ for $8 \mathrm{~h}$. Some parts of the as-prepared samples were annealed at different temperatures ranging from 200 to $800{ }^{\circ} \mathrm{C}$ in an ambient atmosphere at the heating rate of $2{ }^{\circ} \mathrm{C} \min ^{-1}$ for $2 \mathrm{~h}$.

\subsection{Characterization techniques}

The phase purity and crystallinity of the as-prepared samples were characterized by powder X-ray diffraction (PXRD) using a Bruker AXSD8 Advance X-ray diffractometer and the iron-filtered $\mathrm{Cu}-\mathrm{K} \alpha$ radiation $(\lambda=1.54 \AA)$ in the $2 \theta$ range of $10^{\circ}-80^{\circ}$. To analyze the shape and size of the samples, a Field Emission Scanning Electron Microscope (FESEM) NOVA NANOSEM 450 was used. The surface studies were performed on a JASCO FT/IR 6100 instrument. PL spectra were acquired using a Fluorolog Horiba-1057 fluorescence spectrophotometer, equipped with a $400 \mathrm{~W}$ Xe lamp as an excitation source and a Hamamatsu R928 photomultiplier tube (PMT) as the detector. Thermoluminescence measurements of the TL glow spectra of the phosphor material were carried out by using a Nucleonix TLD Reader (Model 1009I) with a constant $5 \mathrm{mg}$ weight of the phosphor sample at a constant heating rate of $5{ }^{\circ} \mathrm{C} \mathrm{s}{ }^{-1}$. For thermoluminescence studies, the phosphor materials were irradiated to gamma rays. The activity of the ${ }^{60} \mathrm{Co}$ gamma source was 2456 Curie on 14 March 2013 (dose rate $=60 \mathrm{~Gy} \mathrm{~min}^{-1}$ ). Its half-life $=5.27$ years. The dose rate of the gamma source $($ at distance $6 \mathrm{~cm})=$ $389000 \mathrm{R} \mathrm{h}^{-1}=3412 \mathrm{~Gy} \mathrm{~h}^{-1}=55 \mathrm{~Gy} \mathrm{~min}^{-1}$. The gamma source emits two gamma quanta having energies $1.17 \mathrm{MeV}$ and $1.33 \mathrm{MeV}$. In TL processes, the heat treatment is done before irradiation, which is necessary to erase any irradiation memory from the dosimetric material. Before irradiation and after irradiation all the samples were kept inside the black box, which prevents external or environmental effects on the TL samples.

\section{Results and discussion}

\subsection{Structural and morphological investigations of $\mathrm{NaGdF}_{4}: \mathbf{T b}^{3+}$ phosphors}

The composition, crystallinity and phase purity of the as-prepared phosphors were first examined by XRD. Fig. 1(a-g) compares typical
XRD patterns of the as-synthesized $\mathrm{NaGdF}_{4}: x \% \mathrm{~Tb}^{3+}(x=0,0.5,1,2$, 3,4 , and 5) phosphors. All of the samples exhibited sharp diffraction peaks that can be readily indexed to the pure hexagonal-phase $\beta$ $\mathrm{NaGdF}_{4}$ (space group: $P 6_{3} / \mathrm{m}$ ). The calculated lattice parameters are $a=6.0 \AA, c=3.6 \AA$, which are in good agreement with the reported data (JCPDS no. 27-0699). No secondary phase was observed in the XRD patterns, revealing that the $\mathrm{Tb}^{3+}$ ions have been effectively doped into the $\beta-\mathrm{NaGdF}_{4}$ host lattice without any phase transformation.

The size and morphology of the as-prepared samples were characterized by field emission scanning electron microscopy (FESEM). As shown in Fig. $2(\mathrm{a}-\mathrm{g}), \beta-\mathrm{NaGdF}_{4}: x \% \mathrm{~Tb}^{3+}$ crystals possess a highly uniform and monodispersed spherical-shaped structure with an average diameter of $\sim 300 \mathrm{~nm}$.

3.1.1 The effects of thermal treatment on the crystal structure and morphology of $\mathrm{NaGdF}_{4}: \mathbf{T b}^{3+}$ phosphors. The effects of thermal treatment were studied in $\beta-\mathrm{NaGdF}_{4}: \mathrm{Tb}^{3+}$ phosphors. This was particularly done in order to realize and study the favorable thermoluminescence characteristics. The $\beta-\mathrm{NaGdF}_{4}: \mathrm{Tb}^{3+}$ crystals were annealed at different temperatures for $2 \mathrm{~h}$. The influence of thermal treatment on the crystal structure, morphology and optical properties was determined by choosing $\beta-\mathrm{NaGdF}_{4}: 3 \% \mathrm{~Tb}^{3+}$ phosphor crystals labeled as $\beta$-NGF, and NGF- $X$, where $X=200,300,400 \ldots$ $800{ }^{\circ} \mathrm{C}$ for the corresponding temperatures. The XRD patterns of $\beta$-NGF-200 to $600{ }^{\circ} \mathrm{C}$ are displayed in Fig. S1 (ESI $\dagger$ ). Fig. 3 demonstrates the XRD patterns of $\beta$-NGF and NGF-700-800 ${ }^{\circ} \mathrm{C}$. From XRD patterns in Fig. S1 (ESI $\dagger$ ) and Fig. 3, it demonstrates that the samples remain in their pure hexagonal phase up to $600{ }^{\circ} \mathrm{C}$. At $700{ }^{\circ} \mathrm{C}$, the

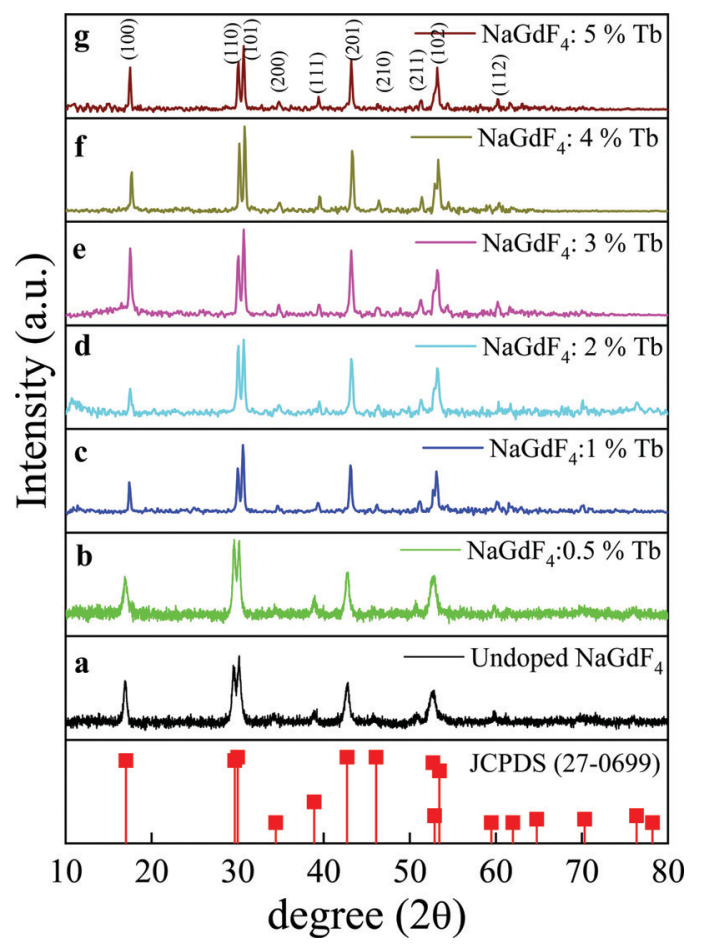

Fig. 1 The XRD patterns of $\beta-\mathrm{NaGdF}_{4}: x \% \mathrm{~Tb}^{3+}(x=0,0.5,1,2,3,4,5)$ $(a-g)$ and the standard data of the hexagonal $\beta-\mathrm{NaGdF}_{4}$ (JCPDS- 27-0699) as a reference. 


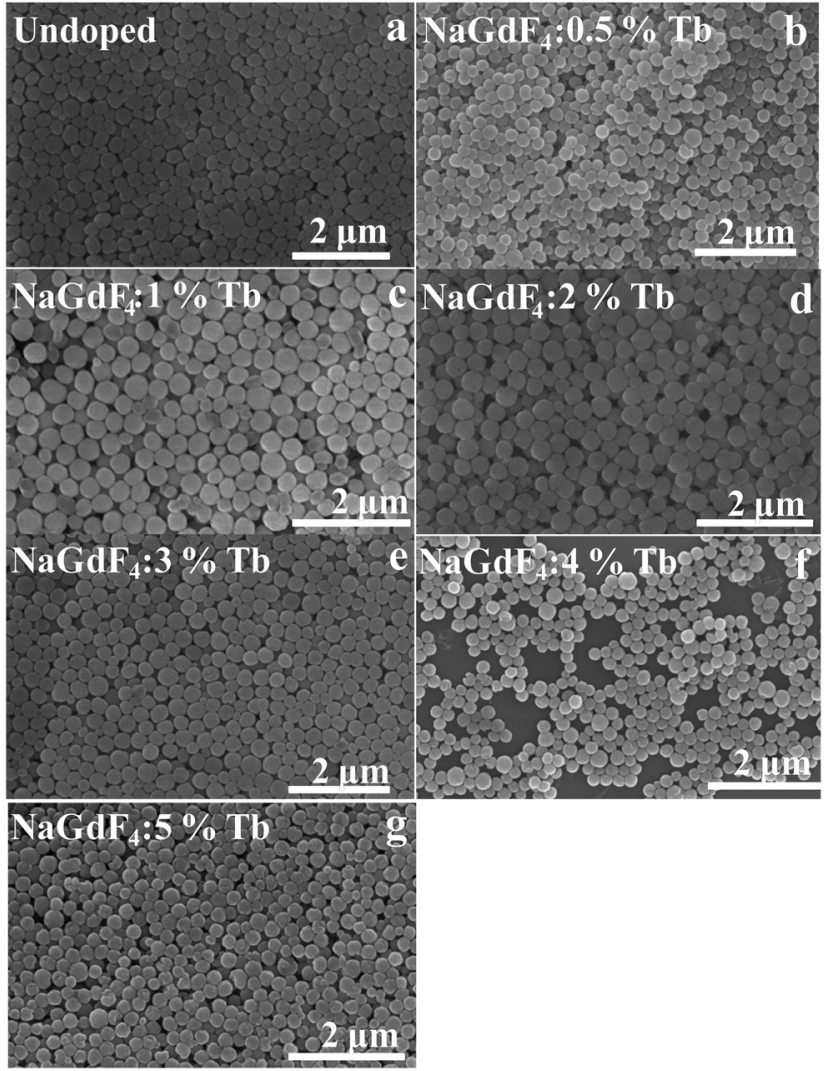

Fig. 2 The FESEM images of $\beta-\mathrm{NaGdF}_{4}: x \% \mathrm{~Tb}^{3+}$ crystals $(x=0,0.5,1,2,3,4,5)$ $(a-g)$ showing the spherical morphology of the as-prepared $\beta-\mathrm{NaGdF}_{4}: x \% \mathrm{~Tb}^{3+}$ phosphors.

phase transformation was initiated from the hexagonal to the cubic phase. Therefore, at $700{ }^{\circ} \mathrm{C}$ and $800{ }^{\circ} \mathrm{C}$, the XRD pattern consisted of mixed phases, i.e., there were peaks from both the hexagonal and cubic phases. Moreover, it is noteworthy that the diffraction peaks of all samples possessed a relatively narrow full width at half maximum (FWHM), indicating that the crystalline phosphor particles had better crystallinity, which is beneficial for luminescence emission.

The effects of annealing on the morphology of the as-prepared phosphors were also studied and are shown in Fig. 4(a-d). It can be clearly seen that the well-dispersed and uniform spherical morphology was transformed into irregular block-like structures of nonuniform size with increasing annealing temperatures.

Based on the above results, it can be inferred that the $\beta$-NGF samples remained in a stable state, and retained their original morphology and crystal structure at low temperatures. When annealed at a higher temperature of $700{ }^{\circ} \mathrm{C}, \beta-\mathrm{NaGdF}_{4}$ crystals obtained enough energy to undergo a phase transformation from the hexagonal to the cubic phase and the $\mathrm{NaGdF}_{4}$ crystals fused into each other and agglomerated, giving rise to the irregular block-like morphology.

\subsection{FTIR study}

The FTIR spectra of the as-prepared, 500 and $700{ }^{\circ} \mathrm{C}$-annealed $3 \%$ $\mathrm{Tb}^{3+}$-doped $\mathrm{NaGdF}_{4}$ phosphor crystals in the wavenumber range of $1000-4000 \mathrm{~cm}^{-1}$ are shown in Fig. 5. For the as-prepared $\mathrm{NaGdF}_{4}$

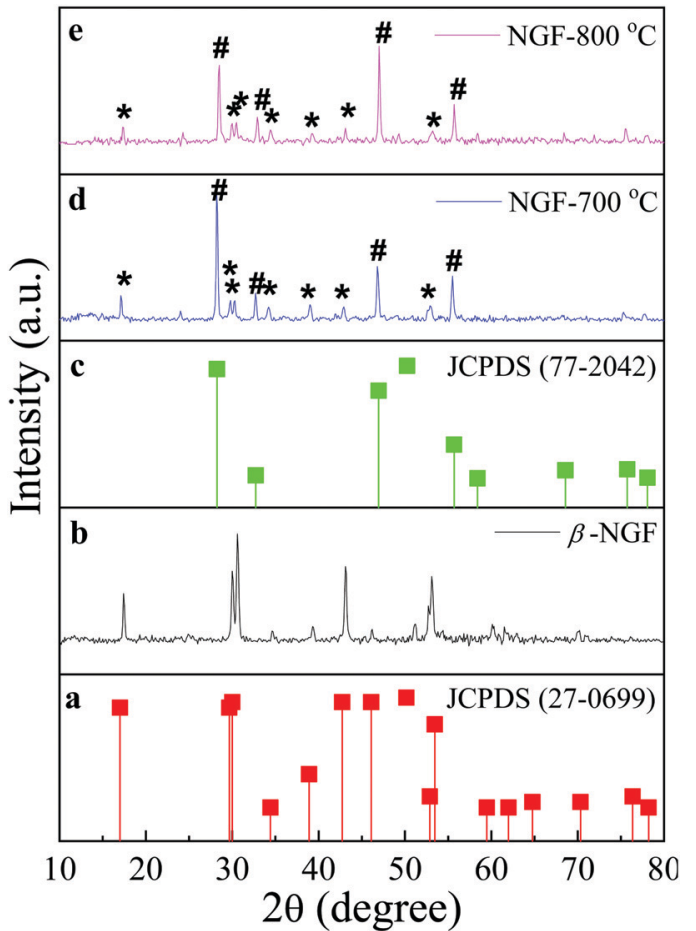

Fig. 3 The XRD patterns of the $\mathrm{NaGdF}_{4}: 3 \% \mathrm{~Tb}^{3+}$ phosphor crystals obtained after annealing at different temperatures for $2 \mathrm{~h}$, labelled as $\beta$-NGF (b) for the as-prepared pristine pure hexagonal phase $\mathrm{NaGdF}_{4}: \mathrm{Tb}^{3+}$ phosphor and annealed samples labelled as NGF- $X\left(X=700{ }^{\circ} \mathrm{C}\right.$ and $\left.800{ }^{\circ} \mathrm{C}\right)(\mathrm{d}$ and e). The standard data of hexagonal $\beta-\mathrm{NaGdF}_{4}$ (JCPDS- 27-0699) and cubic phase $\alpha-\mathrm{NaGdF}_{4}$ (JCPDS- 77-2042) (a and c) as a reference. Diffraction peaks corresponding to the hexagonal phase $\beta-\mathrm{NaGdF}_{4}$ are marked with an asterisk (*) and peaks for the cubic phase $\alpha-\mathrm{NaGdF}_{4}$ are marked with a hash (\#).

phosphor crystals, the band at $\sim 1586 \mathrm{~cm}^{-1}$ can be assigned to the $\mathrm{C}=\mathrm{O}$ asymmetric stretching vibration of the $-\mathrm{COO}^{-}$group and the band at $\sim 1396 \mathrm{~cm}^{-1}$ corresponds to the symmetric stretching vibration of $\mathrm{C}=\mathrm{O}$ in $-\mathrm{COO}^{-}$group of tri-sodium citrate (TSC). This reveals the capping of tri-sodium citrate on the surface of the as-prepared phosphor particles. A broad band at $\sim 3450 \mathrm{~cm}^{-1}$ could be ascribed to the stretching vibrations of $-\mathrm{OH}$ groups as well as to the presence of non-dissociated $\mathrm{OH}$ groups of citrate and molecular water present on the surface of phosphor particles. ${ }^{28,29}$ It can be clearly seen from Fig. 5 that the bands for $-\mathrm{OH}$ groups were diminished upon heat treatment, i.e., at the annealing temperatures of 500 and $700{ }^{\circ} \mathrm{C}$. It was well demonstrated by TGA-DSC studies that the decomposition of tri-sodium citrate occurs in three steps at temperatures ranging from $160{ }^{\circ} \mathrm{C}$ to $700{ }^{\circ} \mathrm{C} \cdot{ }^{30,31}$ Accordingly, the FTIR spectra (Fig. 5) revealed that the intensity of the bands for the $-\mathrm{COO}^{-}$functional group of the TSC ligand was greatly reduced at $700{ }^{\circ} \mathrm{C}$. These results suggest the decomposition of surface ligands at higher annealing temperatures that may lead to the agglomeration of particles, resulting in the increase in particle size as revealed by FESEM images.

\subsection{Photoluminescence studies of $\boldsymbol{\beta}-\mathrm{NaGdF}_{4}: \mathrm{Tb}^{3+}$}

Fig. 6 compares the excitation (a) and emission (b, c) photoluminescence spectra of $\mathrm{Tb}^{3+}$ ion-doped $\mathrm{NaGdF}_{4}$ crystals. No emission lines 


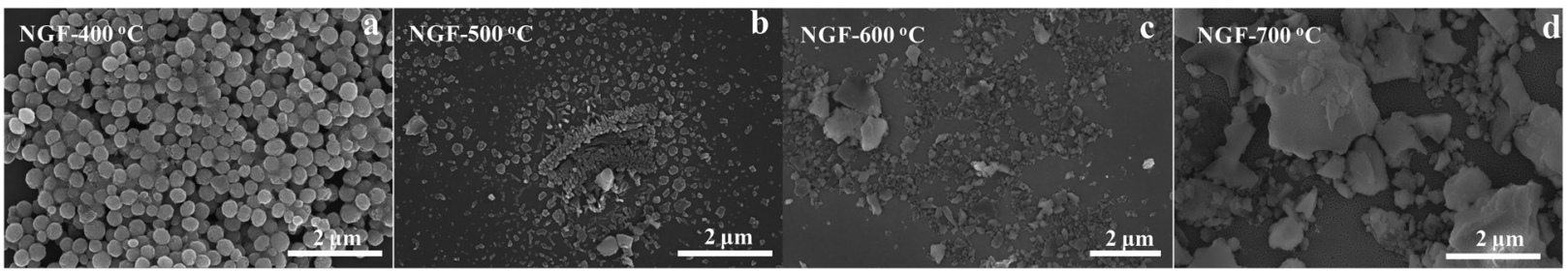

Fig. 4 The FESEM images of $\mathrm{NaGdF}_{4}: 3 \% \mathrm{~Tb}^{3+}$ crystals; NGF-X (X=400,500,600, $\left.700{ }^{\circ} \mathrm{C}\right)(\mathrm{a}-\mathrm{d})$ annealed at different temperatures for $2 \mathrm{~h}$. At $700{ }^{\circ} \mathrm{C}$, microblock-like structures were formed.

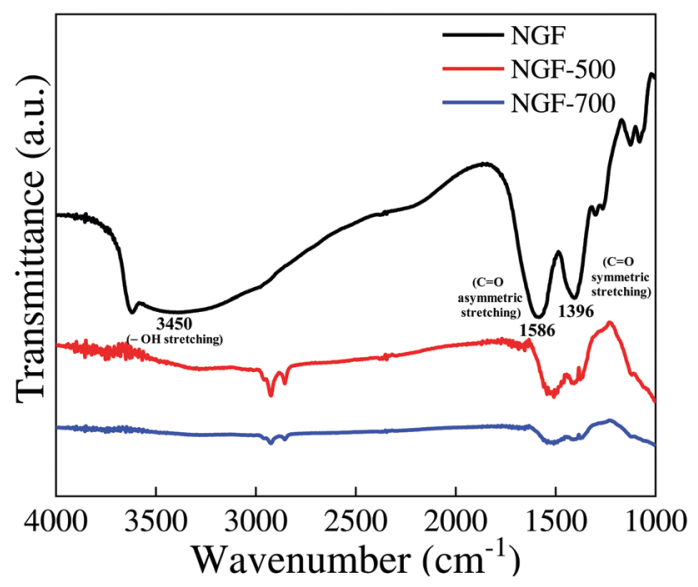

Fig. 5 FTIR spectra of the as-prepared (NGF), $500{ }^{\circ} \mathrm{C}$ (NGF-500) and $700{ }^{\circ} \mathrm{C}$ (NGF-700) annealed $\mathrm{NaGdF}_{4}: 3 \% \mathrm{~Tb}^{3+}$ phosphor crystals.

appeared for the undoped samples and in all the doped $\beta-\mathrm{NaGdF}_{4}: x \% \mathrm{~Tb}^{3+}(x=0,0.5,1,2,3,4$, and 5$)$ samples, the peakpositions in the excitation and emission spectra remained similar, and the bands differed only in their relative intensities. The excitation and emission intensities increased with increasing dopant concentration. The excitation spectrum monitored at $\lambda_{\mathrm{ex}}=540 \mathrm{~nm}$ had several excitation lines originating from the $\mathrm{f}-\mathrm{f}$ transitions of $\mathrm{Gd}^{3+}$ and $\mathrm{Tb}^{3+}$ ions in the UV spectral region. The excitation lines at, $\sim 228 \mathrm{~nm}, \sim 273 \mathrm{~nm}$ and $\sim 312$ can be assigned to the transition from the ${ }^{8} \mathrm{~S}_{7 / 2}$ ground state to the excited states ${ }^{6} \mathrm{D}_{9 / 2},{ }^{6} \mathrm{I}_{7 / 2}$, and ${ }^{6} \mathrm{P}_{7 / 2}$ of $\mathrm{Gd}^{3+}$ ions. ${ }^{32,33}$ The weak excitation lines at $\sim 356 \mathrm{~nm}$ and $\sim 375 \mathrm{~nm}$ correspond to the transitions from the ${ }^{7} \mathrm{~F}_{6}$ ground state to the ${ }^{5} \mathrm{D}_{2}$ and ${ }^{5} \mathrm{G}_{6}$ excited states of $\mathrm{Tb}^{3+}$ ions, as shown by the arrow in the inset of Fig. 6(a). ${ }^{34}$ The obtained emission spectra monitored at $\lambda_{\mathrm{ex}}=\sim 228 \mathrm{~nm}$ and $\sim 273 \mathrm{~nm}$ showed intense emissions in the regions of $480-680 \mathrm{~nm}$, which are due to the ${ }^{5} \mathrm{D}_{4} \rightarrow{ }^{7} \mathrm{~F}_{J}(J=3,4,5,6)$ transitions of $\mathrm{Tb}^{3+}$ ions. Specifically, the four prominent emission peaks centered at $\sim 484, \sim 540, \sim 580$, and $\sim 615 \mathrm{~nm}$, originated from the transitions of ${ }^{5} \mathrm{D}_{4} \rightarrow{ }^{7} \mathrm{~F}_{6},{ }^{5} \mathrm{D}_{4} \rightarrow{ }^{7} \mathrm{~F}_{5},{ }^{5} \mathrm{D}_{4} \rightarrow{ }^{7} \mathrm{~F}_{4}$, and ${ }^{5} \mathrm{D}_{4} \rightarrow$ ${ }^{7} \mathrm{~F}_{3}$, respectively. ${ }^{35}$ Among these transitions, the green emission ${ }^{5} \mathrm{D}_{4} \rightarrow{ }^{7} \mathrm{~F}_{5}$ at $\sim 540 \mathrm{~nm}$ is the most intense emission, which corresponds to a magnetic dipole transition. Comparison of the excitation intensity bands of the $\beta-\mathrm{NaGdF}_{4}: \mathrm{Tb}^{3+}$ phosphor particles monitored at $540 \mathrm{~nm}$ showed that the intensity of the $\sim 228 \mathrm{~nm}^{8} \mathrm{~S}_{7 / 2}$ to ${ }^{6} \mathrm{D}_{9 / 2}$ transition band was more intense than the other bands. From Fig. 6(d), the combination of the two emission intensity effects under excitation at $228 \mathrm{~nm}$ and $273 \mathrm{~nm}$ showed that the emission intensity of the emission spectrum monitored at $228 \mathrm{~nm}$ was enhanced dramatically as compared to emission intensity obtained under $273 \mathrm{~nm}$ excitation.

The optical properties of inorganic materials are strongly dependent on their size, morphology, doping, crystallinity, thermal treatment and other parameters, that affect the band structure. Among these, studies of the effects of thermal treatment in inorganic phosphor are rarely conducted.

3.3.1 The effects of thermal treatment on the photoluminescence properties of $\mathrm{NaGdF}_{4}: \mathbf{T b}^{3+}$. The photoluminescence (PL) emission spectra monitored at $\lambda_{\mathrm{ex}}=228 \mathrm{~nm}$ for $\mathrm{NaGdF}_{4}: \mathrm{Tb}^{3+}$ phosphor particles annealed at different temperatures for $2 \mathrm{~h}$ are illustrated in Fig. 7. The emission intensity of the $\mathrm{NaGdF}_{4}: \mathrm{Tb}^{3+}$ phosphor increased with increasing annealing temperature. Moreover, apart from the intense green emissions in the region of 480-680 $\mathrm{nm}$ due to ${ }^{5} \mathrm{D}_{4} \rightarrow{ }^{7} \mathrm{~F}_{J}(J=3,4,5,6)$ transitions of $\mathrm{Tb}^{3+}$ ions, upon heat treatment, the emission spectra also additionally yielded weak blue emissions in the regions of 400-450 nm, which are due to the ${ }^{5} \mathrm{D}_{3} \rightarrow{ }^{7} \mathrm{~F}_{J}(J=3$, 4,5 , and 6) transitions of $\mathrm{Tb}^{3+}$ ions. Specifically, the emission bands at $\sim 410$, and $\sim 432 \mathrm{~nm}$ were attributed to the emission transitions of ${ }^{5} \mathrm{D}_{3} \rightarrow{ }^{7} \mathrm{~F}_{5}$ and ${ }^{5} \mathrm{D}_{3} \rightarrow{ }^{7} \mathrm{~F}_{4}$, respectively. The luminescence intensity was significantly enhanced ( $\sim 9$ times) at the annealing temperature of $700{ }^{\circ} \mathrm{C}$. The reason behind the enhancement of PL upon annealing at higher temperatures might be the following. (1) Higher temperature leads to the fusion and agglomeration of particles, resulting in the formation of bigger blocks, which can effectively decrease the surface defects and consequently decrease non-radiative losses and increase radiative emission. (2) Volatilization of luminescence-quenching organic ligands/groups adsorbed on the surface of phosphor particles at higher temperatures leads to the enhancement of emission intensity. As verified by FTIR observations, the band for structural and non-dissociated - $\mathrm{OH}$ groups of citrate and water molecules was diminished at a higher annealing temperature. Such residual groups/species with high phonon frequency are expected to quench the luminescence efficiency. The removal or desorption and decomposition of these quenching groups from the particle surface during the annealing process may result in the enhancement of the luminescence intensity. ${ }^{27,36,37}$

\section{Thermoluminescence dosimetric properties}

\subsection{Glow curve optimization}

The thermoluminescence glow curve is a measure of the intensity of the emitted light as a function of temperature. These glow curve structures are of particular importance as they are the main 

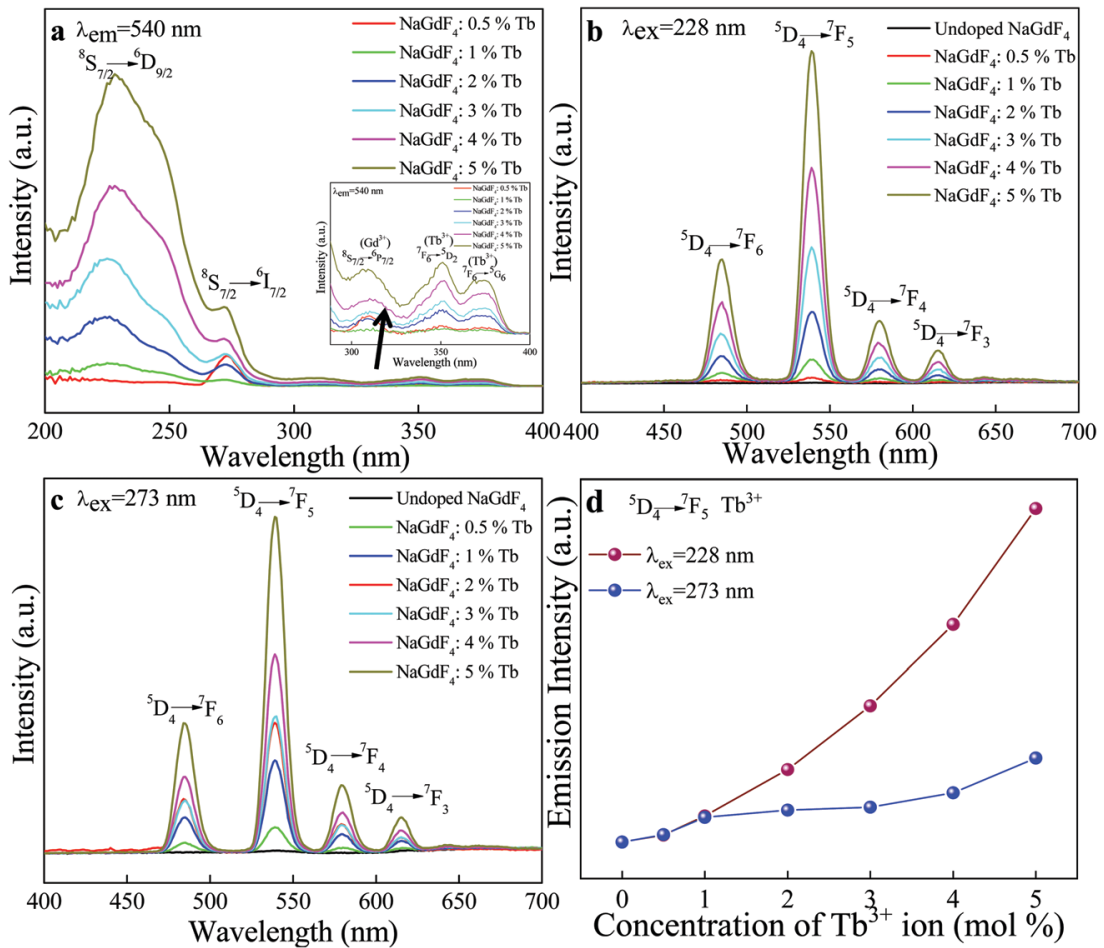

Fig. 6 Comparison of the static photoluminescence excitation spectra monitored at $\lambda_{\mathrm{em}}=540 \mathrm{~nm}(\mathrm{a})$, and emission spectra monitored at $\lambda_{\mathrm{ex}}=228 \mathrm{~nm}$ and $\lambda_{\mathrm{ex}}=273 \mathrm{~nm}(\mathrm{~b}$ and $\mathrm{c})$ of $\beta-\mathrm{NaGdF}_{4}: x^{0} \mathrm{~Tb}^{3+}(x=0,0.5,1,2,3,4,5)$ crystals with different concentrations. The photoluminescence intensity of the ${ }^{5} \mathrm{D}_{4} \rightarrow{ }^{7} \mathrm{~F}_{5}$ transition of the $\mathrm{Tb}^{3+}$ ions as a function of dopant concentration (d) at different excitation wavelengths $\lambda_{\mathrm{ex}}=228 \mathrm{~nm}$ and $\lambda_{\mathrm{ex}}=273 \mathrm{~nm}$.

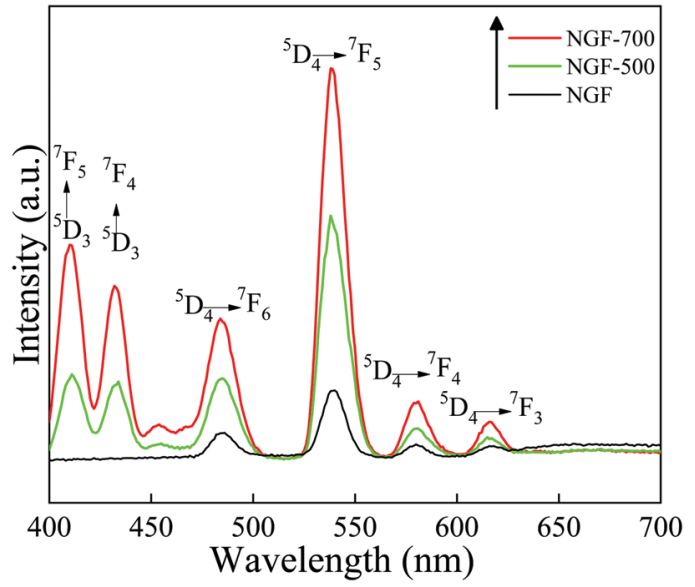

Fig. 7 The photoluminescence emission spectra of the pristine $\mathrm{NaGdF}_{4}: 3 \%$ $\mathrm{Tb}^{3+}$ phosphor crystals and $\mathrm{NaGdF}_{4}: 3 \% \mathrm{~Tb}^{3+}$ phosphor annealed at $500{ }^{\circ} \mathrm{C}$ and $700{ }^{\circ} \mathrm{C}$, monitored at $\lambda_{\text {ex }}=228 \mathrm{~nm}$. The emission intensity increased at higher annealing temperatures.

indicators of whether or not a material can be employed for $\mathrm{TL}$ dosimetry. The favorable glow curve structure, TL sensitivity and luminescence efficiency are strongly influenced by the concentration of impurities/dopants and the thermal treatment of the phosphor material. ${ }^{38}$ Therefore, the investigation of the dependency of the glow curve structure on the dopants concentration and annealing temperatures is a significant research area in developing and exploring new TL materials. Keeping this point in mind, we conducted the optimization by annealing $\mathrm{NaGdF}_{4}: \mathrm{x} \% \mathrm{~Tb}^{3+}$ $(x=0,0.5,1,2,3,4,5)$ phosphors at different temperatures from 200-800 ${ }^{\circ} \mathrm{C}$ for 2 h. Fig. S2(a-g) (ESI $\dagger$ ) and Fig. 8 show typical TL glow curves of pristine $\mathrm{NaGdF}_{4}: x \% \mathrm{~Tb}^{3+}$ and annealed $\mathrm{NaGdF}_{4}: x \%$ $\mathrm{Tb}^{3+}$ phosphor irradiated by gamma radiation of dose $1 \mathrm{kGy}$ from the ${ }^{60} \mathrm{Co}$ gamma source. For the pristine $\mathrm{NaGdF}_{4}: \mathrm{x} \% \mathrm{~Tb}^{3+}$ phosphor, an asymmetric TL peak appeared at around $340{ }^{\circ} \mathrm{C}$ (Fig. S2(a), ESI ${ }^{\dagger}$ ). Upon successive thermal pretreatments at 200,300 and $400{ }^{\circ} \mathrm{C}$, almost all samples showed wide broadly distributed, multiple, low intensity and asymmetric TL peaks at 120,250 , and $340{ }^{\circ} \mathrm{C}$, respectively (see Fig. S2(b-d), ESI $\dagger$ ). As mentioned above, the TL peak shape and position are among the important deciding factors for a useful TLD material. At annealing temperatures 500 and $600{ }^{\circ} \mathrm{C}$, for all doping concentrations, two peaks appeared: one at a lower temperature, $145{ }^{\circ} \mathrm{C}$, with high intensity, and another lowintensity peak at $350{ }^{\circ} \mathrm{C}$ (Fig. S2(e and f), ESI $\dagger$ ). Since the lowtemperature peaks $\left(145^{\circ} \mathrm{C}\right)$ possess high intensity, this means that the samples possess increased numbers of shallow traps and are also likely to fade at faster rates and thus, are not suitable for long term measurements. ${ }^{39,40}$ Fig. S2(g) (ESI $\dagger$ ) demonstrates the TL glow curves of samples annealed at $800{ }^{\circ} \mathrm{C}$. For 0.5 and $1 \% \mathrm{~Tb}$ concentration, a single prominent TL glow peak was obtained at around $218{ }^{\circ} \mathrm{C}$; however, it possessed a very broad distribution, which may consist of several overlapping peaks.

At annealing the temperature of $700{ }^{\circ} \mathrm{C}$, two TL peaks were obtained for $\mathrm{NaGdF}_{4}: x \% \mathrm{~Tb}^{3+}(x=1,2,4,5)$, one at low temperature $\sim 145{ }^{\circ} \mathrm{C}$ and another at high temperature $\sim 230^{\circ} \mathrm{C}$. On comparing the TL glow curves of the $\mathrm{NaGdF}_{4}: x_{0} \mathrm{~Tb}^{3+}(x=0,0.5,1,2,3,4,5)$ phosphor, pristine and annealed at different temperatures $\left(200-800{ }^{\circ} \mathrm{C}\right)$, we obtained the most satisfactory and favorable results 


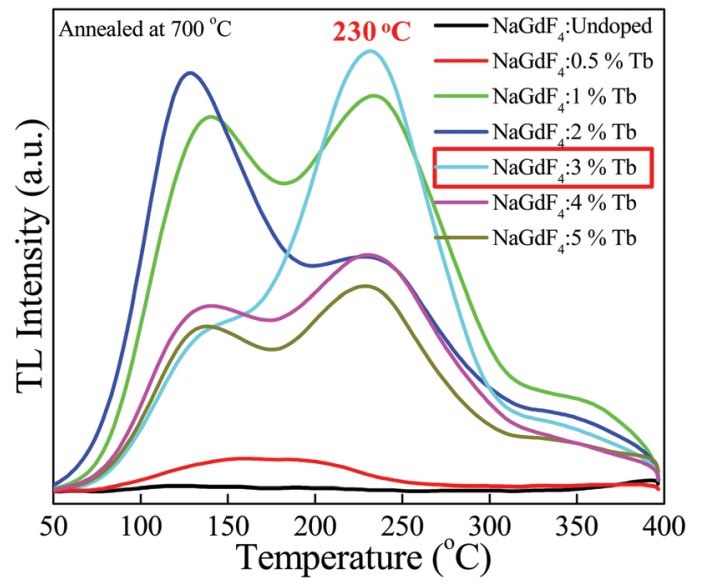

Fig. 8 Thermoluminescence glow curve optimization of the $\mathrm{NaGdF}_{4}: x \% \mathrm{~Tb}^{3+}$ $(x=0,0.5,1,2,3,4,5)$ phosphor annealed at $700^{\circ} \mathrm{C}$, irradiated at a gamma dose of $1 \mathrm{kGy}$. NaGdF $: 3 \% \mathrm{~Tb}^{3+}$ showed the most suitable glow curve at $230{ }^{\circ} \mathrm{C}$.

for the $\mathrm{NaGdF}_{4}: 3 \% \mathrm{~Tb}^{3+}$ phosphor annealed at $700{ }^{\circ} \mathrm{C}$. As can be seen from Fig. 8, the $\mathrm{NaGdF}_{4}: 3 \% \mathrm{~Tb}^{3+}$ phosphor annealed at $700{ }^{\circ} \mathrm{C}$ showed the most intense appropriate Gaussian shape single-peak at $230{ }^{\circ} \mathrm{C}$ with a very small shoulder at around $145^{\circ} \mathrm{C}$. The absence of a low-temperature glow peak in $\mathrm{NaGdF}_{4}: 3 \% \mathrm{~Tb}^{3+}$ might be due to the elimination of surface traps in the phosphor sample. The hightemperature peak is suggestive of the presence of deeper traps in the phosphor sample, and consequent stable and efficient thermoluminescence dosimetric behavior. This TL feature obtained for the $\mathrm{NaGdF}_{4}: 3 \% \mathrm{~Tb}^{3+}$ phosphor annealed at $700{ }^{\circ} \mathrm{C}$ (i.e. dosimetric glow curve temperature position at $230{ }^{\circ} \mathrm{C}$ ) is very close to commercially available standard thermoluminescence dosimetric materials such as $\mathrm{LiF}: \mathrm{Mg}, \mathrm{Cu}, \mathrm{Si}, \mathrm{Li}_{2} \mathrm{~B}_{4} \mathrm{O}_{7}: \mathrm{Mn}, \mathrm{CaSO}_{4}: \mathrm{Dy}$ or $\mathrm{Tm}^{2,41}$

It is worth noting that no thermoluminescence glow curves appeared for undoped $\mathrm{NaGdF}_{4}$ crystals at any annealing temperature at the gamma dose of $1 \mathrm{kGy}$. Therefore, it is likely that the presence of $\mathrm{Tb}^{3+}$ dopant ions increases the number of trapping/luminescent centers in the host system, which results in the realization of thermoluminescence properties in the $\mathrm{NaGdF}_{4}: \mathrm{Tb}$ phosphor system. In general, the kinds of traps/luminescent centers created by $\gamma$-irradiation are mostly affected by the dopant concentration and annealing temperature; thus, the appropriate dopant concentration and annealing temperature help to maintain the defect equilibrium and stabilization of traps ${ }^{38}$ and consequently, the realization of thermoluminescence characteristics. In the present case, $\mathrm{NaGdF}_{4}$ doped with $3 \%$ concentration of $\mathrm{Tb}^{3+}$ ion annealed at $700{ }^{\circ} \mathrm{C}$ rendered the most favorable thermoluminescence properties; thus, we opted for the $\mathrm{NaGdF}_{4}: 3 \% \mathrm{~Tb}^{3+}$ phosphor annealed at $700{ }^{\circ} \mathrm{C}$ for further TL dosimetric characteristics such as dose-response, fading, reproducibility, trapping parameters and activation energy.

The crystal structure of hexagonal $\mathrm{NaGdF}_{4}$ has three different crystallographic sites for the $\mathrm{Gd}^{3+}$ and $\mathrm{Na}^{+}$cations; these sites are called the $1 \mathrm{a}, 1 \mathrm{f}$ and $2 \mathrm{~h}$ sites. The three types of cationic sites include a nine-fold coordinated position where the 1a site is occupied by $\mathrm{Gd}^{3+}$ ions, another nine-fold coordinated where $1 \mathrm{f}$ is occupied randomly by $\mathrm{Gd}^{3+}$ and $\mathrm{Na}^{+}$ions, and a six-fold coordinated $2 \mathrm{~h}$ site that is half occupied by $\mathrm{Na}^{+}$ions and half vacancies. The two different $\mathrm{Gd}^{3+}$ sites are both coordinated by nine fluorine $\left(\mathrm{F}^{-}\right)$atoms in the form of tricapped trigonal prisms. ${ }^{42,43}$ The dopant $\mathrm{Ln}^{3+}\left(\mathrm{Tb}^{3+}\right.$ in present case) ions substitute for $\mathrm{Gd}^{3+}$ ion sites in the $\mathrm{NaGdF}_{4}$ crystal lattice. ${ }^{25}$ These vacancies and the dopant ions may act as trapping sites and radiative recombination centers. ${ }^{42,44}$ However, detailed study and useful insight are required to better understand the nature of the traps/sites, defects and radiative recombination centers associated with the $\mathrm{NaGdF}_{4}$ : $\mathrm{Tb}$ phosphor system.

4.1.1 Linear dose-response. The amount of radiation dose absorbed by a phosphor material is directly proportional to the TL glow curve response. To study the glow curve response, the phosphor was irradiated with various doses of gamma radiation. The variation of the TL glow peak intensity of the $\mathrm{NaGdF}_{4}: 3 \% \mathrm{~Tb}^{3+}$ phosphor with accumulated dose was studied and the intensities of the TL signals as a function of dose are shown in Fig. 9(a and b). The glow curve mainly consisted of a single dosimetric peak at $230{ }^{\circ} \mathrm{C}$, with a small shoulder at $145{ }^{\circ} \mathrm{C}$ and the glow peak position remained the same at all doses; only a variation in the TL intensity was observed. The TL response against dose can be computed by the following equation:

$$
\begin{gathered}
I=a D^{b}, \\
\log (I)=\log (a)+b \log (D)
\end{gathered}
$$

where $I=$ TL intensity, $D=$ dose, $a=$ constant and the slope $(b)=$ the linearity factor, which is determined by a linear fit of $\log (I)$ versus $\log (D)$. Fig. 9(b) shows the dose-response in a log-log scale. A dose-response line that is the linear fit yields the slope of value close to 1 ( $b=0.98 \pm 0.025)$, with regression coefficient $R^{2}=0.99$ in a log-log scale that conveys relatively good linearity of the signal in the dose-response in the range of $100 \mathrm{~Gy}$ to $20 \mathrm{kGy}$. It can be clearly seen that the TL glow curve intensity linearly increases with increasing gamma doses from $100 \mathrm{~Gy}$ to $20 \mathrm{kGy}$, and beyond 20 kGy the TL intensity is saturated. This change in the relative intensity of the glow peaks was mainly attributed to the change in the population of the luminescent centers (LC)/trapping centres (TC). The linearity and further saturation are well explained by the Defect Interaction Model (DIM) and Track Interaction Model (TIM). Both models are based on the assumptions concerning the microscopic distribution of trapped charge carriers upon the absorption of gamma radiation. ${ }^{45}$ At low doses, the specific numbers of electron and hole traps exist in pairs. These electronhole traps are such that no extra center can exist between the pairs, and the recombination of various trapping/luminescent centres (TCs/LCs) occurs entirely within the tracks. Electrons escaping the tracks were intercepted by the non-radiative competitive centres (CC) in the intermediate region. The competitive centers do not affect recombination and therefore, the TL signal increases linearly with the irradiation and is proportional to the gamma $(\gamma)$ dose. However, as the dose increases further, the space between electron-hole pair traps/neighboring tracks, or the distance between luminescence centers, is reduced and more overlapping tracks occur that may not give extra TL in the material. As a result, a further rise in the dose levels leads to saturation due to the limited number of available traps vacant in the phosphor. ${ }^{46-48}$ In a nutshell, the number of defects/trapping centers created in 

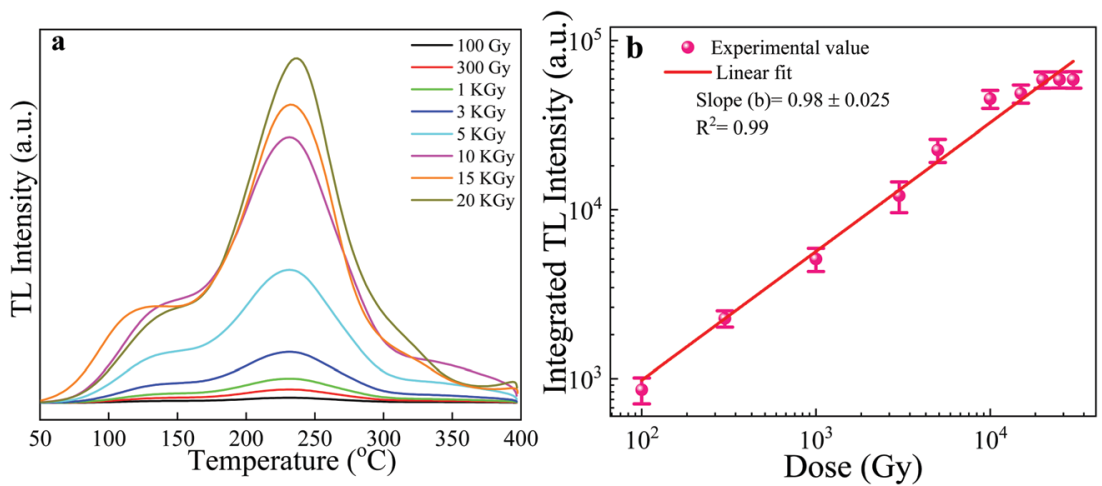

Fig. $9 \mathrm{TL}$ glow curves of the $\mathrm{NaGdF}_{4}: 3 \% \mathrm{~Tb}^{3+}$ phosphor irradiated with various doses (100 Gy to $20 \mathrm{kGy}$ ) of gamma rays from a ${ }^{60} \mathrm{Co}$ source (a). Linear TL response of the $\mathrm{NaGdF}_{4}: 3 \% \mathrm{~Tb}^{3+}$ phosphor as a function of irradiation dose (b).

the particles keeps on increasing with the increasing dose till saturation is obtained. This explains the linearity of the $\mathrm{NaGdF}_{4}: 3 \% \mathrm{~Tb}^{3+}$ phosphor over the dose range $100 \mathrm{~Gy}-20 \mathrm{kGy}$ and further saturation. This linear behavior of the phosphor is a highly important and useful property for the dosimetric application. It can, therefore, be concluded that the as-synthesized phosphor material can be used as a TL mapping and radiation monitoring material.

It is worth mentioning that the as-synthesized $\mathrm{NaGdF}_{4}: 3 \% \mathrm{~Tb}$ phosphor showed linear behavior up to very higher doses of $20 \mathrm{kGy}$, and further achieved saturation levels. The possible reason behind its dose-response at a high dose might be related to the effective atomic number $\left(Z_{\text {eff }}\right)$ of the $\mathrm{NaGdF}_{4}: \mathrm{Tb}$ phosphor material. It is usually assumed and observed that the phosphor materials with high effective atomic number respond to relatively high energy and dose ranges and are thus particularly useful for high dose applications. ${ }^{49}$ The effective atomic number $\left(Z_{\text {eff }}\right)$ of $\mathrm{NaGdF}_{4}: \mathrm{Tb}$ is high enough at about 53; therefore, it is expected to show TL response possibly in relatively high doses. Traditional and commercial TL dosimetric phosphor systems have been designed, which provide high sensitivity and low fading and have been put to successful operation. However, the dose range of these traditional phosphors is normally not over $100 \mathrm{~Gy}{ }^{7,9}$ while higher doses need to be measured in technological and medical applications; for example, the sterilization of medical products, and irradiation of food products. This property of linear behavior up to very higher doses makes the $\mathrm{NaGdF}_{4}: 3 \% \mathrm{~Tb}$ phosphor useful for its application in estimating high exposures of gamma rays, high-radiation dose dosimetry and other applications.

\subsection{Fading and reproducibility}

The fading characteristic of a phosphor indicates its ability to retain the charge pairs created during irradiation over the storage period. Thus, fading studies reveal the stability of the TL signal in the phosphor material with respect to time, and is an important point in the choice of a TLD. The fading investigation of the $\mathrm{NaGdF}_{4}: 3 \% \mathrm{~Tb}^{3+}$ phosphor was carried out upon gamma irradiation of a typical dose of $10 \mathrm{kGy}$. The TL dose-response (integral intensity) of the $\mathrm{NaGdF}_{4}: 3 \% \mathrm{~Tb}^{3+}$ phosphor as a function of time was recorded and is shown in Fig. 10. To evaluate the fading of the
TL signal, the irradiated phosphor samples were stored and protected from light at room temperature, and then the TL signals were registered by taking the same weight of sample each time at different time intervals up to 90 days, and the TL responses versus the storage time were plotted. The TL fading curve indicated the presence of two-step fading before and after $\sim 10$ days. The first few days (we can say 4-5 days), it depicted the resulting afterglow. In the afterglow, luminescence was emitted from a TL phosphor immediately after irradiation, and after few days it retained the electrons from trap centers due to atmospheric thermal effects. Such initial rapid decay (fading) followed by a decrease in the decay rate over long storage periods is explained by the tunnelling of carriers from the trap to the recombination centre. ${ }^{50}$ Overall, it was found that less than $10 \%$ fading was observed during the first twenty days but thereafter, the intensity remained almost constant; the result is well within the acceptable limit for standard TL dosimetric phosphor materials. The as-prepared phosphor showed low fading, i.e., the ability to store dosimetric information for a long time.

The comparative thermoluminescence characteristics of the $\mathrm{NaGdF}_{4}: 3 \% \mathrm{~Tb}^{3+}$ phosphor with standard TLD materials are shown in Table 1.

Reproducibility is also an important parameter for verifying the potential of a phosphor material in TLD. For testing the reproducibility of the $\mathrm{NaGdF}_{4}: 3 \% \mathrm{~Tb}^{3+}$ phosphor, the samples were annealed, irradiated to $10 \mathrm{kGy}$ gamma dose and the TL signal was recorded with the same heating rate of $5{ }^{\circ} \mathrm{C} \mathrm{s}^{-1}$. This process of annealing $\rightarrow$ irradiating $\rightarrow$ readouts was repeated 7 times. As seen from Fig. 11, the TL response and readouts of samples did not change appreciably after a number of repetitions. Thus, reasonable reproducibility was also found for this phosphor for dose measurements.

\subsection{Experimental TL glow curve study}

This method is useful for estimating the number and position of individual thermoluminescence (TL) peaks within a complex glowcurve. The experimental TL glow curve analysis is primarily the systematic thermal cleaning of TL peaks in the glow curve. ${ }^{51}$ $T_{\mathrm{m}}-T_{\text {stop }}$ analysis and the Initial Rise Method (IRM) are among the important methods in the experimental glow curve study for the 


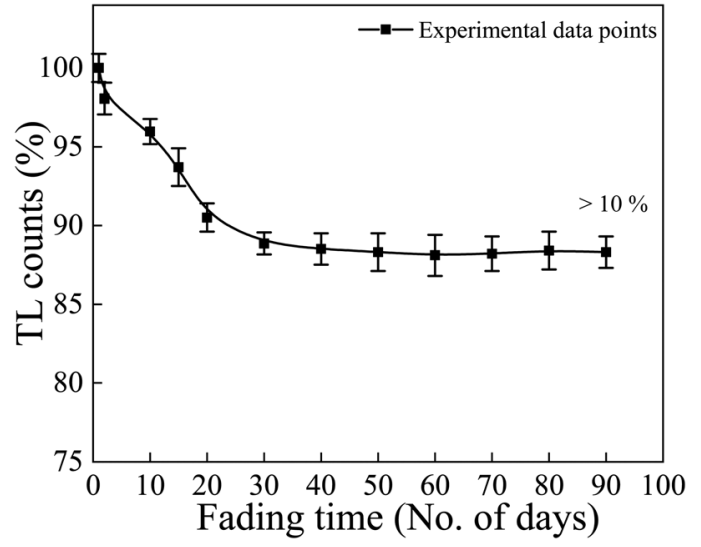

Fig. 10 Fading curve of the $\mathrm{NaGdF}_{4}: 3 \% \mathrm{~Tb}^{3+}$ phosphor at a $10 \mathrm{kGy}$ dose of gamma-ray irradiation at different time intervals, up to 90 days.

estimation of trapping parameters. The $T_{\mathrm{m}}-T_{\text {stop }}$ curves allow the individual peaks, i.e., the numbers of glow peak components in the complex glow curve of the phosphor, to be identified and the results are used as input parameters and thus can be analysed by the curvefitting GCD procedure. In the present study, we used the $\mathrm{NaGdF}_{4}: 3 \% \mathrm{~Tb}^{3+}$ phosphor irradiated with a $10 \mathrm{kGy}$ dose of gamma rays. In the $T_{\mathrm{m}}-T_{\text {stop }}$ analysis, first, we heated the phosphor material at a uniform heating rate of $5{ }^{\circ} \mathrm{C}$ from room temperature to the chosen temperature $\left(T_{\text {stop }}\right)$. After heating, the phosphor sample was allowed to rapidly cool to room temperature and was again reheated to the next temperature ( $\left.T_{\text {stop }}\right)$ in steps of $5{ }^{\circ} \mathrm{C}$. This process was repeated for different values of $T_{\text {stop }}(50,55,60 \ldots$ to . . .390, 395, $400{ }^{\circ} \mathrm{C}$ ) through the entire glow curve, and the position of the peak temperature $T_{\mathrm{m}}$ (temperature corresponding to maximum intensity for the particular $T_{\text {stop }}$ value) was noted; i.e., the cycle of heating, recording, cooling, and again heating was carried out up to the final temperature of $400{ }^{\circ} \mathrm{C}$. In this process, we obtained a single TL curve for each $T_{\text {stop }}$ value from which the $T_{\mathrm{m}}$ value was recorded and then a graph of $T_{\mathrm{m}}$ as a function of $T_{\text {stop }}$ was plotted. A stepwise curve was obtained as shown in the inset image of Fig. 12, which was useful in determining the activation energy for each TL curve. The IRM method was subsequently employed. According to the IRM method, at the beginning of the TL glow peak, the concentration of trapped electrons changes only by a small amount with temperature, so that the first- and general-order TL equations are simplified as $I(T) \propto A \exp (-E / k T)$, where $A$ is a constant, $I(T)=$ TL intensity, $T=$ absolute temperature, $k=$ Boltzmann's factor and $E=$ trap depth, and the TL intensity is independent of the order of kinetics. A plot of $\ln (I)$ versus $1 / T$ would yield a straight line with a slope of $-E / k T$, from which the activation energy $(E)$ can be determined. ${ }^{51-54}$

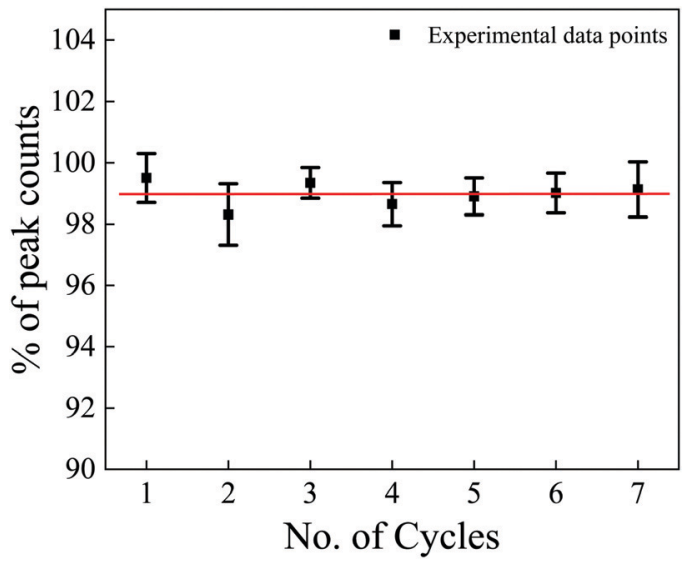

Fig. 11 Reproducibility curve of the $\mathrm{NaGdF}_{4}: 3 \% \mathrm{~Tb}^{3+}$ phosphor irradiated with 10 kGy gamma rays.

We plotted the slope of the straight line $(\ln (I)$ vs. $1 / T)$ with each heating step interval of $5{ }^{\circ} \mathrm{C}$ to obtain the activation energy. ${ }^{46,55}$ The activation energies thus found were then plotted against the temperature to which the sample was heated, which often resulted in the "staircase"-shaped $E-T$ curve as shown in Fig. 12. Each plateau region in the staircase corresponds to the approximate position/trapping state and the activation energy of an individual peak. ${ }^{51,55}$ Fig. 12 illustrates the five TL trapping levels with the first plateau region observed in the temperature range of 80 to $105{ }^{\circ} \mathrm{C}$, corresponding to the trap depth/activation energy of $\sim 1.10 \mathrm{eV}$. Similarly, the second to fifth plateau regions were found in the range of 130 to $155{ }^{\circ} \mathrm{C}$, 175 to $210{ }^{\circ} \mathrm{C}, 240$ to $270{ }^{\circ} \mathrm{C}$, and 310 to $360{ }^{\circ} \mathrm{C}$ corresponding to trap depth/activation energies of $\sim 1.28 \mathrm{eV}, \sim 1.39 \mathrm{eV}$, $\sim 1.66 \mathrm{eV}$, and $\sim 1.60 \mathrm{eV}$, respectively. The trap depth or activation energy, $E(\mathrm{eV})$ is the thermal energy required to release the trapped electrons and holes from their respective trap centers. These activation energies in the phosphor material indicate shallow and deeper trap levels within the band gap of the phosphor material. The value of $E(\mathrm{eV})$ is high for releasing electrons from deep trapping sites and is low for releasing electrons from shallow trapping sites. If the value of the activation energy $(E)$ is high, the glow peak occurs at a relatively higher trap and the corresponding trap created is stable, resulting in minimal fading of the corresponding TL glow peak and vice versa. As can be clearly seen from Fig. 12, five plateaus were found, which suggests that the TL glow curve overlapped with five glow peaks. The overlapped peaks can be separated and consequently, the trap parameters of each peak can be determined by using the glow curve deconvolution (GCD) method.

Table 1 Comparison of the thermoluminescence characteristics of the $\mathrm{NaGdF}_{4}: 3 \% \mathrm{~Tb}^{3+}$ phosphor with standard $\mathrm{TLD}_{\mathrm{D}}$ materials

\begin{tabular}{|c|c|c|c|c|c|c|c|}
\hline TL phosphor & $\begin{array}{l}\text { Effective atomic } \\
\text { number }\left(Z_{\text {eff }}\right)\end{array}$ & $\begin{array}{l}\text { Main } \\
\text { peak }\left({ }^{\circ} \mathrm{C}\right)\end{array}$ & $\begin{array}{l}\text { Emission } \\
\text { maximum (nm) }\end{array}$ & Fading & $\begin{array}{l}\text { Dose } \\
\text { range }\end{array}$ & Sensitivity & $\begin{array}{l}\text { Detection } \\
\text { limit }\end{array}$ \\
\hline Standard TLD (LiF:Mg,Cu,P) & 8.14 & 210 & 368 & $5 \% /$ year & $0.2 \mu \mathrm{Gy}-10 \mathrm{~Gy}$ & 40 & $0.2 \mu \mathrm{Gy}$ \\
\hline Standard TLD $\mathrm{Li}_{2} \mathrm{~B}_{4} \mathrm{O}_{7}: \mathrm{Mn}^{2}$ & 7.3 & 220 & 605 & $4 \% /$ month & $0.1 \mathrm{mGy}-3 \mathrm{~Gy}$ & 0.40 & $0.1 \mathrm{mGy}$ \\
\hline $\mathrm{NaGdF}_{4}: \mathrm{Tb}$ & 53 & 230 & 540 & $\begin{array}{l}>10 \% \text { in } \\
3 \text { months }\end{array}$ & 100 Gy-20 kGy & 0.15 & $\sim 90$ Gy \\
\hline
\end{tabular}




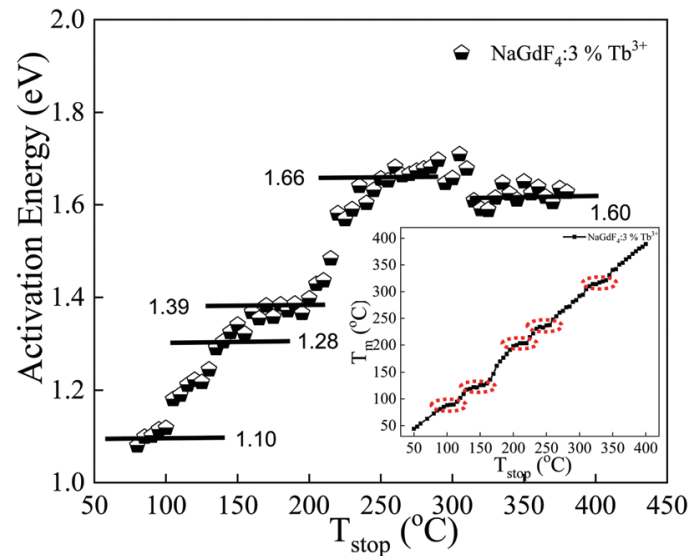

Fig. 12 Activation energy (eV) vs. $T_{\text {stop }}\left({ }^{\circ} \mathrm{C}\right)$ plot resulting from the IR method after the $T_{m}-T_{\text {stop }}$ procedure for the $\mathrm{NaGdF}_{4}: 3 \% \mathrm{~Tb}^{3+}$ phosphor irradiated with gamma radiation of $10 \mathrm{kGy}$ doses. A plot of $T_{\mathrm{m}}$ as a function of $T_{\text {stop }}$ for the $\mathrm{NaGdF}_{4}: 3 \% \mathrm{~Tb}^{3+}$ phosphor as an inset image.

\subsection{Glow curve deconvolution (GCD) for dosimetric parameter evaluation}

The glow curve is characteristic of the different trap levels that lie within the band gap of the phosphor material. Thus, to characterize the TL thermograms, it is necessary to evaluate their trapping parameters and the analysis of these trap levels is useful for estimating the localized trap depth. The dosimetric characteristics of the phosphor mainly depend on the kinetic parameters. Deconvolution of TL glow curves is a common tool for the analysis of TL glow curves and thus, the characterization of the nature of traps. This method is used to evaluate TL kinetics parameters that include trap depth $(E)$, frequency factor $(s)$, and order of kinetics $(b)$ for a given peak in the glow-curve. These parameters reveal the stability of traps/luminescent centers. The trap depth or the thermal activation energy $(E)$ is the energy needed to free the trapped electrons. The frequency factor conveys the value in the order of the lattice vibration frequency and the order of kinetics gives the information about whether or not the re-trapping of trapped charge carriers took place upon heating. ${ }^{56,57}$ TL glow curve deconvolution (GCD) is a very well-known method for analyzing the complex TL mechanism, which includes multiple peak glow curves. After the irradiation of the phosphor material, ionization takes place and electrons get trapped in the different trapping levels. During the TL process, traps recombine and this process depends on many factors such as the rate of temperature change, the thermal release of electrons from traps, escape frequency factor, re-trapping probabilities, etc. Thus, to determine the associated overlapping peak within the glow curve and to estimate the corresponding trapping parameters $E, b$ and $s$, the obtained glow curves were de-convoluted using a glow curve de-convolution Excel spreadsheet program. ${ }^{58}$ Fig. 13 represents the deconvoluted graph for the $\mathrm{NaGdF}_{4}: 3 \% \mathrm{~Tb}^{3+}$ phosphor annealed at $700{ }^{\circ} \mathrm{C}$ irradiated with a $10 \mathrm{kGy}$ gamma dose. In the glow curve deconvolution analysis, we determined trapping parameters of the glow curve such as trap depth $(E)$, frequency factor $(s)$, order of kinetics $(b)$, and figure of merit (FOM), with the accurate fitting of multiple glow peaks using Kitis equations. ${ }^{59}$ Depending on the shape of the glow peak, the probability of the de-trapping and

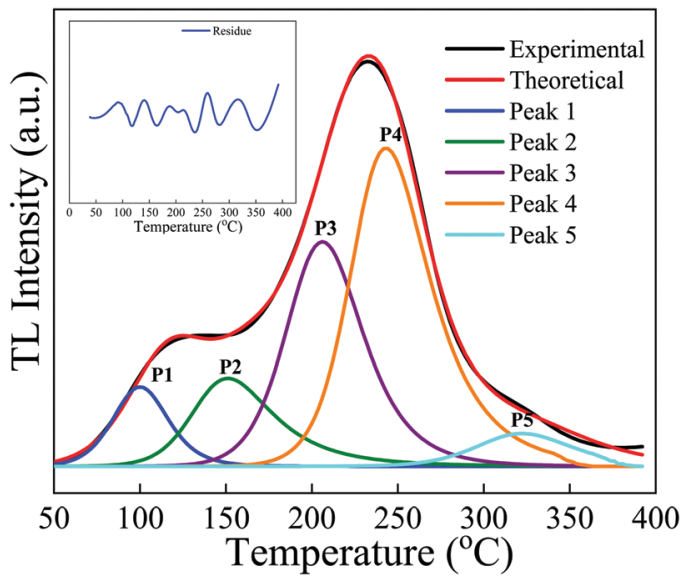

Fig. 13 The deconvoluted glow curves of the $\mathrm{NaGdF}_{4}: 3 \% \mathrm{~Tb}^{3+}$ phosphor recorded after irradiation with a dose of $10 \mathrm{kGy}$ gamma rays using the GCD program.

re-trapping glow peaks is divided into three types, i.e., first-order, second-order, and general-order kinetics. In the present study, general-order kinetics were used; the equation is as follows:

$$
\begin{aligned}
I(T)= & I_{\mathrm{m}} b^{\left(\frac{b}{b-1}\right)} \exp \left(\frac{E}{k T} \frac{T-T_{\mathrm{m}}}{T_{\mathrm{m}}}\right)\left[(b-1) \frac{T^{2}}{T_{\mathrm{m}}^{2}}\left(1-\frac{2 k T}{E}\right)\right. \\
& \left.\times \exp \left(\frac{E}{k T} \frac{T-T_{\mathrm{m}}}{T_{\mathrm{m}}}\right)+1+(b-1) \frac{2 k T_{\mathrm{m}}}{E}\right]^{-\frac{b}{b-1}}
\end{aligned}
$$

where, $I(T)$ is the TL intensity at temperature $T(\mathrm{~K}), I_{\mathrm{m}}$, is the highest peak intensity, $T_{\mathrm{m}}$ is the temperature matching the maximum peak intensity $I_{\mathrm{m}}, E$ is the trap depth (eV), $b$ is the order of kinetics, and $k$ is the Boltzmann's constant $\left(8.6 \times 10^{-5} \mathrm{eV} \mathrm{K}^{-1}\right)$.

Similarly, the frequency factor, i.e., the attempt to escape the frequency is give as

$$
S=\frac{\beta E}{k T_{\mathrm{m}}^{2}\left(1+(b-1) \frac{2 k T_{\mathrm{m}}}{E}\right)} \exp \left(\frac{E}{k T_{\mathrm{m}}}\right)
$$

where, $\beta$ is a heating rate, i.e., $5^{\circ} \mathrm{s}^{-1}$.

The peak was then generated theoretically using these parameters and was separated from the main experimental glow curve. The calculated kinetics (trapping) parameters for the $\mathrm{NaGdF}_{4}: 3 \%$ $\mathrm{Tb}^{3+}$ phosphor are summarized in Table 2, which convey that the trap depth of the phosphor increases with increasing temperature. The value of the activation energy varied from $1.0 \mathrm{eV}$ to $1.66 \mathrm{eV}$; i.e., these peaks were formed at comparably deeper sites within the band gap of the phosphor, which illustrates the trapping of electrons in deep trap centers with appreciable trap depth in the TL process. The maximum error for the experimental and theoretical curves is approximately $\pm 0.03 \%$. The figure of merit (FOM), which is an important tool for checking the performance or accuracy of fitting between experimental data and theoretical data, was found to be only $2.2 \%$, which indicates that the fit was successful and that revealed the accurate fitting of 5 different peaks within the glow curve as shown in Fig. 13. These results indicate 
Table 2 Trapping parameters of the $\mathrm{NaGdF}_{4}: 3 \% \mathrm{~Tb}^{3+}$ phosphor obtained by using the glow curve deconvolution (GCD) method

\begin{tabular}{llllll}
\hline Sample name & Peaks & Temperature $\left(T_{\mathrm{m}}\right)$ & Order of kinetics $(b)$ & Trap depth $(\mathrm{eV})$ & Frequency factor $\left(\mathrm{s}^{-1}\right)$ \\
\hline $\mathrm{NaGdF}_{4}: 3 \% \mathrm{~Tb}^{3+}$ & 1 & 100 & 1.9 & $1.0 \pm 0.04$ & $7.26 \times 10^{14}$ \\
& 2 & 152 & 1.97 & $1.25 \pm 0.03$ & $1.49 \times 10^{16}$ \\
& 3 & 205 & 1.9 & $1.39 \pm 0.04$ & $8.54 \times 10^{15}$ \\
& 4 & 243 & 1.35 & $1.66 \pm 0.03$ & $3.15 \times 10^{16}$ \\
& 5 & 322 & 2 & $1.60 \pm 0.02$ & $5.01 \times 10^{14}$
\end{tabular}

that the experimental and theoretical curves are in good agreement and overlap each other.

The trapping parameters resulting from the experimental $T_{\mathrm{m}}-T_{\text {stop }}$ study followed by the activation energy $v s . T_{\text {stop }}$ analysis and the theoretical glow curve deconvolution (GCD) match closely and are in good agreement with each other.

\section{Conclusion}

In summary, hexagonal phase monodispersed $\beta-\mathrm{NaGdF}_{4}: x \% \mathrm{~Tb}^{3+}$ $(x=0,0.5,1,2,3,4,5)$ spherical-shaped phosphor crystals were synthesized via a tri-sodium citrate-assisted hydrothermal method. Under UV excitation $\left(\lambda_{\text {ex }}=228 \mathrm{~nm}\right)$, the $\beta-\mathrm{NaGdF}_{4}: x \% \mathrm{~Tb}^{3+}$ phosphor emitted strong green emission corresponding to ${ }^{5} \mathrm{D}_{4} \rightarrow{ }^{7} \mathrm{~F}_{J}(J=6,5,4,3)$ transitions characteristic of $\mathrm{Tb}^{3+}$ ions. The as-prepared samples were annealed at different temperatures $\left(200-800{ }^{\circ} \mathrm{C}\right)$ and the effect of thermal treatment on their structural, morphological, photoluminescence and thermoluminescence properties were studied. At the annealing temperature of $700{ }^{\circ} \mathrm{C}$, XRD peaks of the cubic phase appeared; thus, at higher annealing temperature, the XRD pattern revealed a mixed phase of the cubic and hexagonal phases of the $\mathrm{NaGdF}_{4}$ phosphor. The $\mathrm{NaGdF}_{4}$ crystals fused into each other and agglomerated, giving rise to an irregular block-like morphology. The photoluminescence intensity was enhanced with thermal treatment due to the reduction in non-radiative processes from the surface and the volatilization of luminescence quenching $(-\mathrm{OH})$ groups. Thermoluminescence studies were performed by irradiating the phosphor material with gamma-rays. Optimization of the TL properties revealed that the best dosimetric glow curve for $\mathrm{NaGdF}_{4}: 3 \% \mathrm{~Tb}^{3+}$ annealed at $700{ }^{\circ} \mathrm{C}$ peaked at $230{ }^{\circ} \mathrm{C}$, signifying deeper traps. The $\mathrm{NaGdF}_{4}: 3 \% \mathrm{~Tb}^{3+}$ phosphor showed a linear response over a very wide range of gamma doses from $100 \mathrm{~Gy}$ to $20 \mathrm{kGy}$, then after saturation occurred. The low fading, less than $\sim 10 \%$ fading over the period of 90 days, reasonable reproducibility and a wide linear response range at a higher dose make this phosphor suitable for dosimetry for higher doses and imply excellent dosimetric properties. The $T_{\mathrm{m}}-T_{\text {stop }}$ method revealed five activation plateaus at $1.10 \mathrm{eV}, 1.28 \mathrm{eV}, 1.39 \mathrm{eV}, 1.66 \mathrm{eV}$ and $1.60 \mathrm{eV}$, which present the main contributions for radiation storage. The trapping parameters of trap depth (activation energy), the order of kinetics, and frequency factors were established by the Glow Curve Deconvolution (GCD) method. The trapping parameters resulting from the experimental $T_{\mathrm{m}}-T_{\text {stop }}$ study and theoretical GCD matched very well and are in good agreement with each other. To the best of our knowledge, for the first time, we have studied the thermoluminescence dosimetric properties of terbium ion-doped $\mathrm{NaGdF}_{4}$ phosphors.
Apart from their unique strong photoluminescence properties and expected magnetic properties, which provide the $\mathrm{NaGdF}_{4}: \mathrm{Tb}^{3+}$ phosphor with the potential for application in color displays, LEDs, bimodal bioprobes, drug delivery, etc., the thermoluminescence properties of the $\mathrm{NaGdF}_{4}: \mathrm{Tb}^{3+}$ phosphor have been newly explored for potential new applications in the field of radiation dosimetry.

\section{Conflicts of interest}

There are no conflicts of interest to declare.

\section{Acknowledgements}

Preeti Padhye Kulkarni acknowledges the support from the Council of Industrial and Scientific Research (CSIR), India, grant/file No: 09/137(0598)/2019-EMR-I for financial assistance by providing the Research Associate Fellowship. One of the authors, Dr Mahesh Bhadane, is grateful to the Principal and management of the Rayat Shikshan Sanstha's Dada Patil Mahavidyalaya, Karjat, for the encouragement and help time to time. One of the Authors K. H. Gavhane is thankful to Chhatrapati Shahu Maharaj Research Training and Human Development Institute (SARTHI), Pune, for awarding CMSRF and financial assistance.

\section{References}

1 Thermoluminescent materials, ed. D. R. Vij, PTR Prentice Hall, New Jersey, 1993.

2 B. C. Bhatt and M. S. Kulkarni, Defect Diffus. Forum, 2014, 347, 179-227.

3 D. J. Daniel, O. Annalakshmi, U. Madhusoodanan and P. Ramasamy, J. Rare Earths, 2014, 32, 496-500.

4 N. Salah, S. S. Habib, Z. H. Khan, S. Al-Hamedi and S. P. Lochab, J. Lumin., 2009, 129, 192-196.

5 M. T. Jose, S. R. Anishia, O. Annalakshmi and V. Ramasamy, Radiat. Meas., 2011, 46, 1026-1032.

6 V. Pagonis, G. Kitis and C. Furetta, Numerical and Practical Exercises in Thermoluminescence, Springer Newyork, NY, 2006.

7 R. Chen and S. W. S. McKeever, Theory of Thermoluminescence and Related Phenomenon, World Scientific, 1997.

8 P. J. Fox, R. A. Akber and J. R. Prescott, J. Phys. D: Appl. Phys., 1988, 21, 189-193. 
9 M. S. Bhadane, K. H. Gavhane, P. Kulkarni, S. S. Dahiwale, V. N. Bhoraskar, M. A. More, P. S. Patil and S. D. Dhole, J. Lumin., 2020, 223, 117168.

10 A. Duragkar, A. Muley, N. R. Pawar, V. Chopra, N. S. Dhoble, O. P. Chimankar and S. J. Dhoble, Luminescence, 2019, 34, 656-665.

11 L. Gao, X. Ge, Z. Chai, G. Xu, X. Wang and C. Wang, Nano Res., 2009, 2, 565-574.

12 S. Zeng, G. Ren, C. Xu and Q. Yang, CrystEngComm, 2011, 13, 1384-1390.

13 P. Padhye, S. Sadhu, M. Malik and P. Poddar, RSC Adv., 2016, 6, 53504-53518.

14 P. Padhye, A. Alam, S. Ghorai, S. Chattopadhyay and P. Poddar, Nanoscale, 2015, 7, 19501-19518.

15 J. Zhang, B. Li, L. Zhang and H. Jiang, Chem. Commun., 2012, 48, 4860-4862.

16 J. M. Meruga, W. M. Cross, P. S. May, Q. Luu, G. A. Crawford and J. J. Kellar, Nanotechnology, 2012, 23, 395201.

17 M. H. V. Werts, Sci. Prog., 2005, 88, 101-131.

18 Y. Wang, Y. Liu, Q. Xiao, H. Zhu, R. Lia and X. Chen, Nanoscale, 2011, 3, 3164-3169.

19 C. Sun, C. Carpenter, G. Pratx and L. Xing, Nanoscale Res. Lett., 2011, 6(24), 1-7.

20 J. Heine and K. Müller-Buschbaum, Chem. Soc. Rev., 2013, 42, 9232-9242.

21 V. Sudarsan, F. C. J. M. van Veggel, R. A. Herring and M. Raudsepp, J. Mater. Chem., 2005, 15, 1332-1342.

22 J. Senthilselvan, S. Thomas, L. Anbharasi, D. Sarkar, V. N. K. B. Adusumalli, S. A. Kumar, S. Yamini, M. Gunaseelan, J. Manonmani and V. Mahalingam, J. Mater. Sci.: Mater. Electron., 2019, 30, 20376-20392.

23 M. M. Lezhnina, T. Jüstel, H. Kätker, D. U. Wiechert and U. H. Kynast, Adv. Funct. Mater., 2006, 16, 935-942.

24 L. Tashi, M. Kumar, Z. ul Nisa, N. Nelofar and H. N. Sheikh, New J. Chem., 2020, 44, 1009-1020.

25 M. Banski, A. Podhorodecki, J. Misiewicz, M. Afzaal, A. L. Abdelhady and P. O'Brien, J. Mater. Chem. C, 2013, 1, 801-807.

26 Y. Liu, D. Tu, H. Zhu, R. Li, W. Luo and X. Chen, Adv. Mater., 2010, 22, 3266-3271.

27 A. K. Parchur, A. I. Prasad, A. A. Ansari, S. B. Raia and R. S. Ningthoujam, Dalton Trans., 2012, 41, 11032-11045.

28 T. Samanta, S. Sarkar, V. N. K. B. Adusumallia, A. E. Praveen and V. Mahalingam, Dalton Trans., 2016, 45, 78-84.

29 Y. Na, S. Yang and S. Lee, Desalination, 2014, 347, 34-42.

30 İ. Y. Elbeyli, Hydrometallurgy, 2015, 158, 19-26.

31 C. Cheng, Y. Wen, X. Xu and H. Gu, J. Mater. Chem., 2009, 19, 8782-8788.

32 A. T. M. A. Rahman, K. Vasilev and P. Majewski, J. Colloid Interface Sci., 2011, 354, 592-596.

33 Y. Song, B. Shao, Y. Feng, W. Lü, G. Liu and H. You, Dalton Trans., 2016, 45, 9468-9476.
34 K. Naveen Kumar, R. Padma, Y. C. Ratnakaram and M. Kang, RSC Adv., 2017, 7, 15084-15095.

35 C. Li, Z. Quan, J. Yang, P. Yang and J. Lin, Inorg. Chem., 2007, 46, 6329-6337.

36 D. Yang, D. Chen, H. He, Q. Pan, Q. Xiao, J. Qiu and G. Dong, Sci. Rep., 2016, 6, 29871.

37 J. Song, G. Zhi, Y. Zhang and B. Mei, Nano-Micro Lett., 2011, 3, 73-78.

38 E. Sadeghi, M. Zahedifar and M. K. Shoushtari, Appl. Radiat. Isot., 2018, 136, 111-117.

39 W. F. Hornyak, R. Chen and A. Franklin, Phys. Rev. B: Condens. Matter Mater. Phys., 1992, 46, 8036-8049.

40 S. W. S. Mckeever, Thermoluminescence of solids, Cambridge University Press, Cambridge, 1985.

41 M. Prokic, Nucl. Instrum. Methods, 1980, 175, 83-86.

42 H. Kondo, T. Hirai and S. Hashimoto, J. Lumin., 2003, 102103, 727-732.

43 Q. Zhao, B. Shao, W. Lü, W. Lv, M. Jiao, L. Zhao and H. You, Dalton Trans., 2015, 44, 3745-3752.

44 S. Han, X. Qin, Z. An, Y. Zhu, L. Liang, Y. Han, W. Huang and X. Liu, Nat. Commun., 2016, 7, 13059.

45 S. Mahajna and Y. S. Horowitz, J. Phys. D: Appl. Phys., 1997, 30, 2603-2619.

46 K. H. Gavhane, M. S. Bhadane, A. S. Bhoir, P. P. Kulkarni, B. J. Patil, V. N. Bhoraskar, S. D. Dhole and S. S. Dahiwale, J. Alloys Compd., 2019, 817, 152805.

47 D. L. Monika, H. Nagabhushana, S. C. Sharma, B. M. Nagabhushana and R. Hari Krishna, Chem. Eng. J., 2014, 253, 155-164.

48 S. P. Lochab, P. D. Sahare, R. S. Chauhan, N. Salah, R. Ranjan and A. Pandey, J. Phys. D: Appl. Phys., 2007, 40, 1343-1350.

49 M. S. Bhadane, S. S. Dahiwale, K. R. Sature, B. J. Patil, N. T. Mandlik, V. N. Bhoraskar and S. D. Dhole, J. Alloys Compd., 2017, 695, 1918-1923.

50 C. Furetta, Handbook of Thermoluminescence, World Scientific Publishing Co. Pte. Ltd, Singapore, 1937.

51 S. W. S. Mckeever, Phys. Status Solidi A, 1980, 62, 331-340.

52 M. Gokce, K. F. Oguz, T. Karalı and M. Prokic, J. Phys. D: Appl. Phys., 2009, 42, 105412.

53 O. Q. De Clercq, J. Du, P. F. Smet, J. J. Joos and D. Poelman, Phys. Chem. Chem. Phys., 2018, 20, 30455-30465.

54 S. Akca, M. Oglakci, Z. G. Portakal, N. Kucuk, M. Bakr, M. Topaksu and N. Can, Radiat. Phys. Chem., 2019, 160, 105-111.

55 A. N. Yazici, R. Chen, S. Solak and Z. Yegingil, J. Phys. D: Appl. Phys., 2002, 35, 2526-2535.

56 R. K. Tamrakar, D. P. Bisen, I. P. Sahu and N. Brahme, J. Radiat. Res. Appl. Sci., 2014, 7, 417-429.

57 A. J. J. Bos, Materials, 2017, 10, 1357.

58 D. Afouxenidis, G. S. Polymeris, N. C. Tsirliganis and G. Kitis, Radiat. Prot. Dosim., 2012, 149, 363-370.

59 G. Kitis, J. M. Gomez-Ros and J. W. N. Tuyn, J. Phys. D: Appl. Phys., 1998, 31, 2636-2641. 